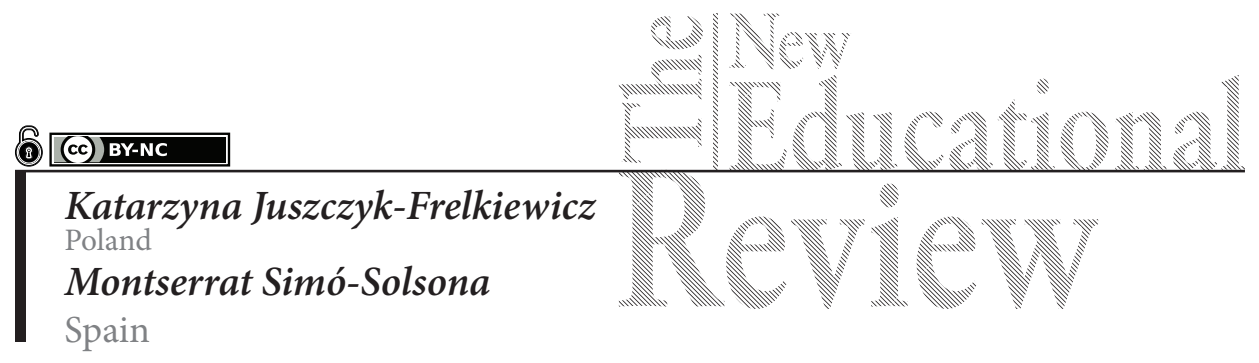

\title{
The End of "Till Death do us Part"? Determinants for Living in a Cohabitation Union in Spain and Poland
}

DOI: 10.15804/tner.2021.65.3.19

\begin{abstract}
Living in a cohabitation union is a more and more popular way of life in the contemporary societies. Changes in family behaviour and formation, such as increases in births outside of marriage, age at first marriage, and divorce have occurred in western countries with different paces and intensity as the elements of Second Demographic Transition (SDT). The aim of the article is to investigate the main determinants which influence attitudes towards living in a cohabitation union in two catholic countries: Spain and Poland. Using the European Social Survey conducted in Poland and Spain in two different moments 2006 and 2018, we carried out ordinal regression models in order to confirm which variables affect more the choice of this union. The results showed that educational level, placement on the left-right scale and religion are the prevailing predictors in both countries and both periods of time, but with different intensities, being greater for the Polish case.
\end{abstract}

Keywords: cohabitation, Poland, Spain, European Social Survey, Second Demographic Transition

\section{Introduction}

The analysis of the changing social reality in the sphere of family life indicates the increasing popularity of cohabitation unions not only in Spain and Poland, but also in all Western European countries (Manting 1994; Nazio 2008). The phenom- 
enon of cohabitation is observed across countries and across life courses due to the formation of many types and different meanings (Hoem 1995; Toulemon 1997; Kiernan 1999; Seltzer 2004; Mills \& Trovato 2000; Nazio 2008; Juszczyk-Frelkiewicz 2014).

For centuries, the traditional family dominated in many societies and it was based on a marriage relationship (following catholic religion) in which children are born, the man was the head of the family and took care of economic security. In turn, the role of a woman in a traditional family was to take care of children and perform household chores (Giddens 1993).

Many researchers indicate that the process of family formation has undergone profound changes in western societies in recent decades (Billari 2005; OECD 2011; Domínguez-Folgueras and Castro-Martin 2013; Furstenberg 2014). Living in the cohabitation union is an effect of these changes, particularly among younger generations (Ermish 2005).

Researchers are invariably interested in finding an explanation of what drives people to enter into cohabitation relationships. Why do some people get married and others choose to live in cohabitation? Several reasons can explain why couples decide to live in cohabitation, including: spending more time together and testing the relationship (Rhoades, Stanley, Markman, 2009), without forgetting reasons related to quality of relationship and owning to formal status, wedding burden and direct normative pressure, as Ø. Kravdal mentioned (1999: 66-67).

The literature shows the increasing scale of the phenomenon of cohabitation (Nazio 2008; Ermisch 2005; Dominguez-Folgueras and Castro-Martin 2013). Many recent studies suggest that young adults in Western Europe may have more opportunities to experience even a second or third cohabiting union (serial cohabitation) in the context of delayed marriage and the increased risk of cohabitation dissolution (Bukodi, 2012; Dommermuth and Wiik, 2014).

However, there are still only a few analyses of which demographic, social and economic features determine the acceptance of life in cohabitation, but there is no such analysis carried out for Spain and Poland based on the European Social Survey data.

The objective of this article is to determine the main factors which affect the attitudes towards living in a cohabitation union in two catholic countries: Spain and Poland.

The structure of the article is as follows: first in theoretical part, we present the definition of cohabitation and its types. Then, we describe the phenomenon of cohabitation as one of the elements of the Second Demographic Transition (SDT) followed by Lesthaeghe and Neidert (2006) and next we focus on cohabitation 
as a chosen form of life in Spain and Poland. We also take into consideration the legal aspects of how a cohabitation union works in both countries. After describing methodological aspects, we present the main results of the European Social Survey in terms of the agreement to living in cohabitation. Finally, we present conclusions.

\section{Emerging cohabitation as a free choice of living}

There are many definitions of cohabitation in the literature on the subject. Problems with determining the duration of a relationship or the frequency of living together as partners do not allow for its precise formulation. Nevertheless, researchers pointed out some common features. Many foreign authors (Ermisch 2005; Kiernan 2001) define cohabitation in no-sexual terms, as a union of two partners living together, between whom there is an intimate realationships, and the relationship is not legalised in the form of marriage. Several types could be considered such as long and short-term consensual unions (Martin and Thery 2001), pre- and post-marital cohabitation (Haskey, 2001), sharing housing, having children and staying together (Heuveline and Timberlake, 2004), future expectations associated with marriage and the duration of the relationship (Casper and Bianchi, 2002), as well as the levels of commitment of each party in a relationship (Smart and Stevens, 2000).

In the 1970s, developed countries began to experience changes in family behaviour and formation, such as increase in births outside of marriage, age at first marriage, and divorce. According to van dee Kaa (1987), these family changes are viewed as inaugurating a new stage of demographic development and they are called the Second Demographic Transition (SDT). Generally, the phenomenon of cohabitation is considered to be one of the characteristic elements of the SDT (Lesthaeghe and Neidert 2006; McLanahan 2004; Surkyn and Lesthaeghe 2004). Following the SDT theory, societies pass through several stages in accepting and adopting cohabitation (Kiernan 2002). Cohabitation in the first stage emerges as a deviant behaviour that few people accept. Later in the diffusion process, cohabitation is adopted by more people and functions as a prelude (or trial) to marriage. Cohabitation then shifts to become equivalent to marriage and an ideal environment for bringing up children (Sobotka and Toulemon 2008).

Consequently, the cohabitation choice is the result of a liberal approach to family life, as well as the growing social acceptance of informal relationships. They are also a response to the expanding individualism, autonomy and focus 
on the self-realisation of individuals in their pursuit of a professional career (Juszczyk-Frelkiewicz 2014: 66).

\section{Cohabitation in Spain and Poland}

The phenomenon of cohabitation occurs in Spain and Poland but with a different scale and intensity. According to the latest censuses conducted in 2011, more Spaniards $(8.8 \%)$ than Poles $(2.1 \%)$ lived in a cohabitation union (CSO 2018: 158). Comparing the data from the 2002 census in Poland, the number of cohabiting couples has increased - in 2002 cohabiting couples with children stood at about 111,000 and without children nearly 87,000, while in 2011 an increase was observed to about 172,000 and 145,000 (respectively) (CSO 2020: 214). Data from Spain shows the same increasing trend. Comparing 2011 to 2001, the number of cohabitation couples went up from $5.9 \%$ to $14.5 \%$, while the number of marriages has fallen (Eurostat 2019). It is also noteworthy that the percentage of same-sex couples getting married since 2005 has been increasing steadily year by year, reaching 3.25\% in 2020 (INE 2020).

The birth of children out of wedlock is directly related to the phenomenon of cohabitation. The share of birth outside marriage in Poland was nearly two times lower than in Spain. In 2013 in Poland it was 23.4 and in Spain 40.9 compared to 2019 when it increased (respectively) to 25.4 and 48.4. Moreover, Spain sees a continuous and systematic increase, while in Poland the trend is rather upward but with slight downward moments (Eurostat 28/06/2021).

When analysing the phenomenon of cohabitation, it should be emphasised that both countries, Spain and Poland, are countries where Catholicism dominates (...). However, Spain is a country where the society is more open and tolerant to new forms of life, while Poland seems to be conservative in this matter. This is indicated by the fact that in Spain cohabitation unions are legally regulated for homosexual and heterosexual couples. Since 2003, the national 2/2003 Law has accepted consensual unions between people from different gender. This law was introduced following some regional legislations from some Autonomous Communities, for instance, Catalonia which has its own competences in this aspect. In 2005, Spain legalised same-sex marriage and made a homosexual union equal to a heterosexual one. In Poland, despite many projects submitted to the Sejm by various political parties (Tomczak and Zawadzka 2018), there is still no legal possibility of registering cohabitation unions - thus, couples living in an informal relationship do not have legal rights, as is the case for married couples. Pursuant to 
Polish regulations, primarily civil, family and guardianship law, as well as tax law, these people are treated as complete strangers to each other.

The quantitative and qualitative studies indicate that the general level of cohabitation in Poland is still low. Nevertheless, young Poles enter into cohabitation relationships before they get married. They also show that cohabitation unions are perceived in Poland as a probationary period preceding marriage rather than avant-garde or deviant behaviour (Mynarska, Matysiak 2010).

As recent studies show, consensual unions in Spain cannot continue to be considered a phenomenon of a marginal nature as was the case at the beginning of the social changes (García-Pereiro et al., 2014; Domínguez y Castro, 2013; Martín-García, 2013; Domínguez-Folgueras, 2013; García-Pereiro, 2011b). Spain is slightly higher than the $8.8 \%$ of the EU- 28 population aged 20 and over which lived in a consensual union in 2011, while Poland is among the countries with the lowest proportions observed (2.1\%), similar to Greece (1.7\%), Malta (2.5\%) and Croatia (2.9\%) (CSO 2018: 158).

\section{Methodology of the research}

The European Social Survey Module Timing of life is the database used in this article. It was carried out in Poland and Spain during rounds three (2006) and nine (2018). In the case of Spain, total N in 2006 included 1876 interviewed people and 1668 in 2018. In Poland, the sample contained 1721 people for 2006 and 1500 for 2018. Descriptive and multivariate analyses are carried out with a quantitative approach. Specifically, ordinal logistic regression analyses were conducted to compare Spain and Poland across time on several independent variables. We were modelling a predictive relationship between more independent variables and an ordered dependent variable using SPSS version 25.

\section{Analysis of determinants for attitudes to living in a cohabitation union}

The results presented previously allow for understanding the real scope of cohabitation as a choice of living together. The next step is to add in our analysis a more subjective perspective related to cohabitation. In order to achieve this objective, we analyse the level of agreement to living with a partner not married to as a dependent variable, comparing both countries and two periods: 2006 and 
2018. Additionally, we complement our analysis exploring the main determinants that can explain the different patterns of agreement in cohabitation terms.

Figure 1 shows the level of agreement to living with a partner not married to (rated from 1, strongly disapprove to 5, strongly approve). Spain is more condescending about the new choices of living with a partner. This trend is maintained over time, when $50 \%$ of cases rated between 3 and 4 in 2006 and this half of population move from 3 to 5 in 2018. Despite this predictable stabilisation, if we look at where the first $50 \%$ of cases are located (median): over time, this has shifted towards greater tolerance of living with a partner not married to, while in 2006 it was up to 3, in 2018 it increased to 4 .

Poland, on the other hand, takes a more conservative position on living with a partner not married to. In 2006, 50\% of the cases are more widespread, between 2 and 4 on a scale of 1 to 5 . It should also be noted that the median is as high as 3 , showing that a relevant number of cases disagree and strongly disagree with the statement. In 2018, there is a significant change: firstly, a lower heterogeneity in the answers (less box extent), 50\% of the cases are more concentrated, from 3 to 4 . Secondly, although there is no greater receptiveness to this attitude comparing to 2006, people who completely disagree are considered outliers. Thus, these opinions are placed further away from the most common ones, i.e. further away from the set. In short, in 2018 Poland has a more similar opinion to Spain.

With the aim to explain in depth the different trends followed by Spain and Poland, we carried out an ordinary regression analysis considering the level of agreement to living with a partner not married to being a dependent variable and some independent variables.

Predictor variables of the agreement level of "cohabitation" include: gender (binary) dummy coded $0=$ female and $1=$ male. Education level treated as a categorical (ordered) variable indicating $1=$ low qualification (isced 1-2) as a reference category; $2=$ medium qualification (isced $3-4$ ) and $3=$ high qualification (isced 5-6). Civil status whether a person is married or civil partnership (coded 1 ) or not married (coded 0 ). Religion coded as a categorical variable indicating 1 (roman catholic) as a reference category, $2=$ other religion and $3=$ no religion. Age and placement on the left-right scale (0 left-10 right) are treated as continuous variables. Main activity in labour market whether a person is active (1) or not active in the labour market (0). Following traditions and customs handed down from the religion or family: important (1) or not important (0). "Are you or have you ever been married" coded $1=$ yes and $0=$ no. "Have you ever given birth to/ fathered a child?" is coded $1=$ yes and $0=$ no. Finally, "approve if a person lives with a partner not married to" is an ordered and categorical variable indicating 


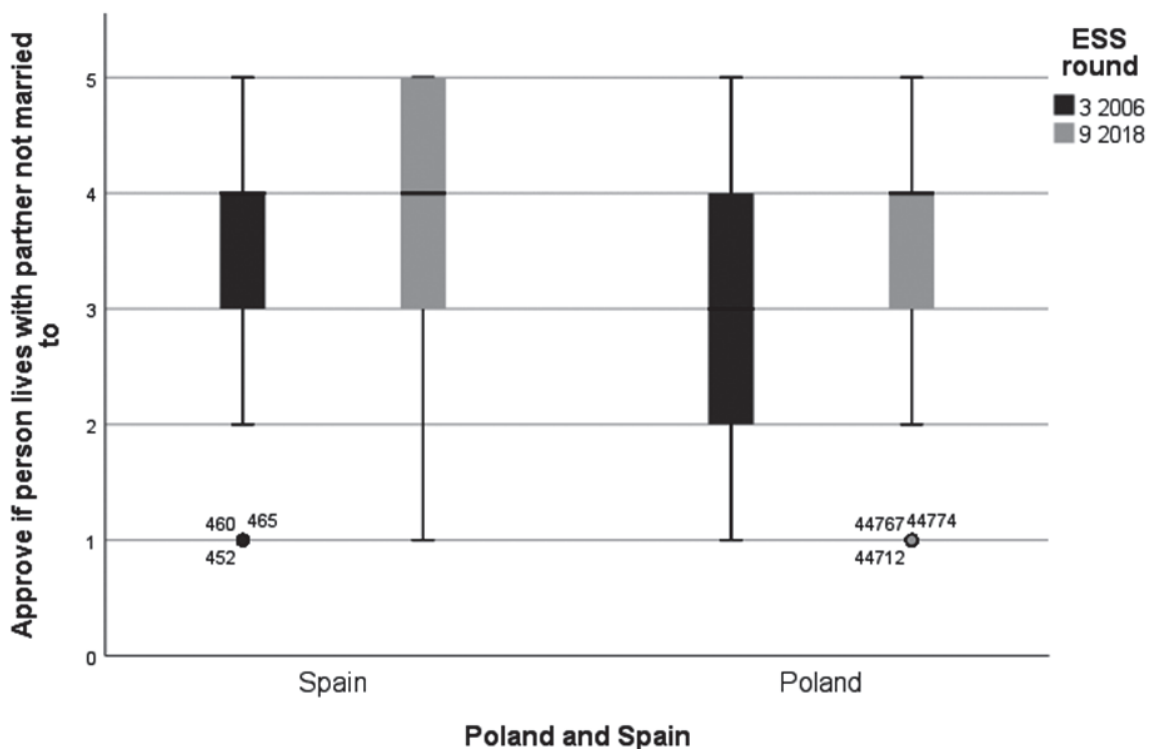

Figure 1. Level of agreement to living with a partner not married to. Spain and Poland. 2006, 2018.

Source: Authors' own elaboration on the data from European Social Survey 2006 and 2018.

people's agreement to the statement. It is coded $1=$ disapprove, $2=$ neither approve nor disapprove and $3=$ approve. The following table presents the exponentiation of the B coefficients, the odds ratio $(\operatorname{Exp}(B))$ and significance tests for each of the independent variables in the models.

In Spain (2006), education level, religion and main activity are positive significant predictors. The odds of a person with a medium qualification being in the approve category of the dependent variable is 1.399 times higher than of a person with low education level. In terms of religion, people who do not profess any religion are more likely to indicate approve to the statement (1.555 odds ratio) than catholic ones. On contrary, people who exercises other religion are less likely to approve cohabitation ( 0.235 odds ratio). The odds of a person who is active in labour market being more likely to agree to the statement is 1.505 times higher than a person who is not occupied in the labour market. In terms of gender, males have a decreasing probability of approving living with a partner not married to than females (odds ratio 0.751). The importance to follow inherited traditions and customs has a negative and significant contribution to the model in Spain in 2006: 
as we expected, those who considered it important to follow traditions are less likely to agree to living with a partner not married to (odds ratio 0.689). Besides, people who identify themselves in the right-wing ideological scale disapprove of cohabitation to a greater extent. Finally, age contributes negatively; the older the person is, the less likely they are to approve cohabitation (0.969).

In the case of Poland (2006), clearer predictors could be observed. Education level and religion provide a significant and positive contribution to the model as in Spain in 2006, but with a higher odds ratio. The higher education level, the higher probability of approving living with a partner not married to. In the case of highly educated people, the figure is more than twice higher comparing to less qualified people. In the case of medium qualification, the odds ratio is 1.504 times higher than that of those who have low qualification. In addition, people who are not religious are more than three times more likely to approve cohabitation than the Catholics (odds ratio 3.115). Following inherited traditions has a more explicit effect in Poland in 2006. People who consider it important to follow traditions are less probable to approve living with a partner not married to (odds ratio 0.420). Age and ideological scale operate as a Spain 2006 model: older and more conservative people are less likely to agree with the statement than younger and leftist people are. Gender and main activity in the labour market are not significant predictors in this case.

Table 1. Ordinal regression models for Spain and Poland in 2006 and 2018.

\begin{tabular}{|c|c|c|c|c|c|c|c|c|c|c|c|c|}
\hline & \multicolumn{3}{|c|}{ Spain 2006} & \multicolumn{3}{|c|}{ Poland 2006} & \multicolumn{3}{|c|}{ Spain 2018} & \multicolumn{3}{|c|}{ Poland 2018} \\
\hline & $\operatorname{Exp}(B)$ & Sig. & & $\operatorname{Exp}(B)$ & Sig. & & $\begin{array}{l}\text { Exp } \\
(B)\end{array}$ & Sig. & & $\begin{array}{l}\text { Exp } \\
\text { (B) }\end{array}$ & Sig. & \\
\hline \multicolumn{13}{|l|}{ Threshold } \\
\hline Disapprove & 0.023 & 0.000 & $* * *$ & 0.076 & 0.000 & $* * *$ & 0.014 & 0.000 & $* * *$ & 0.015 & 0.000 & $* * *$ \\
\hline $\begin{array}{l}\text { Neither approve } \\
\text { nor disapprove }\end{array}$ & 0.135 & 0.000 & $* * *$ & 0.215 & 0.000 & $* * *$ & 0.121 & 0.000 & $* * *$ & 0.035 & 0.000 & $* * *$ \\
\hline \multicolumn{13}{|l|}{ Gender } \\
\hline Men & 0.751 & 0.008 & $* *$ & 0.929 & 0.505 & & 0.787 & 0.055 & & 1.125 & 0.390 & \\
\hline Women & ref. & & & ref. & & & ref. & & & ref. & & \\
\hline \multicolumn{13}{|l|}{ Education level } \\
\hline $\begin{array}{l}\text { High Qualifica- } \\
\text { tion (isced 5-6) }\end{array}$ & 1.184 & 0.262 & & 2.311 & 0.000 & $* * *$ & 0.799 & 0.142 & & 1.744 & 0.003 & $* *$ \\
\hline $\begin{array}{l}\text { Medium qual- } \\
\text { ification (isced } \\
3-4 \text { ) }\end{array}$ & 1.399 & 0.012 & * & 1.504 & 0.003 & ** & 1.127 & 0.448 & & 1.490 & 0.008 & $* *$ \\
\hline
\end{tabular}




\begin{tabular}{|c|c|c|c|c|c|c|c|c|c|c|c|c|}
\hline & \multicolumn{3}{|c|}{ Spain 2006} & \multicolumn{3}{|c|}{ Poland 2006} & \multicolumn{3}{|c|}{ Spain 2018} & \multicolumn{3}{|c|}{ Poland 2018} \\
\hline & $\operatorname{Exp}(B)$ & Sig. & & $\operatorname{Exp}(B)$ & Sig. & & $\begin{array}{l}\operatorname{Exp} \\
(B)\end{array}$ & Sig. & & $\begin{array}{l}\operatorname{Exp} \\
(B)\end{array}$ & Sig. & \\
\hline $\begin{array}{l}\text { Low qualifica- } \\
\text { tion (isced } 1-2 \text { ) }\end{array}$ & ref. & & & ref. & & & ref. & & & ref. & & \\
\hline \multicolumn{13}{|l|}{ Civil status } \\
\hline Other & ref. & & & ref. & & & ref. & & & ref. & & \\
\hline $\begin{array}{l}\text { Married/civil } \\
\text { partnership }\end{array}$ & 0.966 & 0.823 & & 0.932 & 0.685 & & 1.052 & 0.653 & & 0.956 & 0.693 & \\
\hline \multicolumn{13}{|l|}{ Religion } \\
\hline No religion & 1.555 & 0.001 & $* * *$ & 3.115 & 0.000 & $* * *$ & 1.089 & 0.566 & & 1.174 & 0.510 & \\
\hline Other religion & 0.235 & 0.000 & $* * *$ & 0.699 & 0.461 & & 0.121 & 0.000 & $* * *$ & 0.297 & 0.010 & $* *$ \\
\hline $\begin{array}{l}\text { Roman Catho- } \\
\text { lic }\end{array}$ & ref. & & & ref. & & & ref. & & & ref. & & \\
\hline Age & 0.969 & 0.000 & $* * *$ & 0.982 & 0.000 & $* * *$ & 0.981 & 0.000 & $* * *$ & 0.981 & 0.000 & $* * *$ \\
\hline \multicolumn{13}{|l|}{ Main activity } \\
\hline Not occupied & ref. & & & ref. & & & ref. & & & ref. & & \\
\hline Occupied & 1.505 & 0.001 & $* * *$ & 1.068 & 0.593 & & 1.291 & 0.055 & & 1.449 & 0.014 & * \\
\hline $\begin{array}{l}\text { Placement on } \\
\text { left-right scale } \\
\text { (0 left-10 right) }\end{array}$ & 0.897 & 0.000 & $* * *$ & 0.892 & 0.000 & $* * *$ & 0.911 & 0.002 & & 0.795 & 0.000 & $* * *$ \\
\hline \multicolumn{13}{|l|}{$\begin{array}{l}\text { Important to } \\
\text { follow tradi- } \\
\text { tions/customs }\end{array}$} \\
\hline Not important & ref. & & & ref. & & & ref. & & & ref. & & \\
\hline Important & 0.689 & 0.001 & $* * *$ & 0.420 & 0.000 & $* * *$ & 0.897 & 0.414 & & 0.452 & 0.000 & $* * *$ \\
\hline \multicolumn{13}{|l|}{$\begin{array}{l}\text { Are you or have } \\
\text { you ever been } \\
\text { married }\end{array}$} \\
\hline No & ref. & & & ref. & & & ref. & & & ref. & & \\
\hline Yes & 1.184 & 0.470 & & 0.815 & 0.482 & & 0.966 & 0.919 & & 0.457 & 0.074 & \\
\hline \multicolumn{13}{|l|}{$\begin{array}{l}\text { Ever given birth } \\
\text { to/ fathered } \\
\text { a child }\end{array}$} \\
\hline No & ref. & & & ref. & & & ref. & & & ref. & & \\
\hline Yes & 1.077 & 0.691 & & 1.092 & 0.690 & & 1.191 & 0.395 & & 1.611 & 0.094 & \\
\hline $\begin{array}{l}\text { Likelihood ratio } \\
\text { chi-square test }\end{array}$ & 317.018 & 0.000 & $* * *$ & 249.695 & 0.000 & $* * *$ & 114.474 & 0.000 & $* * *$ & 241.277 & 0.000 & $* * *$ \\
\hline Observations & 1588 & & & 1387 & & & 1383 & & & 1176 & & \\
\hline
\end{tabular}

Significance level: ${ }^{\star} \mathrm{P} \leq 0,05 ;{ }^{\star \star} \mathrm{P} \leq 0,01 ;{ }^{* \star} \mathrm{P} \leq 0,001$.

Source: Authors' own elaboration on the data from European Social Survey 2006 and 2018. 
The same model is explored in more recent data in both countries. In the case of Spain in 2018, few predictors are significant, only age, the weight of following traditions and religion. All of them account for a negative contribution. This indicates that an older person, from other religion and somebody who considers it important to follow traditions is less likely to approve living in cohabitation than younger, Roman Catholic and who does not consider it important to follow traditions. Recently in Poland (2018) we have observed a similar pattern as in Spain in 2006. Education level remains a crucial predictor for approving or disapproving of living in cohabitation. In 2018, highly and medium qualified Poles are more likely to indicate a greater agreement to the statement (1.744 times higher in high education level and 1.490 times higher in medium education level). Also, activity in the labour market contributes to the agreement level of cohabitation. The odds of an occupied person who approves living with a partner not married to is 1.449 times higher than a person who is not occupied. Age, placement on the left-right scale and the relevance of traditions provide a negative contribution to the model. People who are older, identify themselves in more right scale position and consider it important to follow traditions are less likely to approve living in cohabitation. As the results present, religion diminishes its contribution to the model and it could be understood as a symptom of an evolution to an open-minded society.

\section{Conclusion}

The ordinal regression analysis indicates which variables affect the level of agreement to living with a person not married to the most. In 2006, attitudes towards cohabitation could be understood through education level and religion (especially higher education and not religious people), in particular in Spain. Also, being active in the labour market contributes to approving living with a partner not married to. Therefore, cohabitation is more accepted by a privileged group, both economically and socially; additionally, with behaviours associated with modernity, high educational and cultural levels. Moreover, the Polish model shows higher odds ratio than the Spanish one, indicating differences being more intense between groups. Despite this trend towards openness, the weight of the more conservative and reluctant-to-change factors continues to be substantial in Poland. People with "right-wing positions" in the ideological scale and "who consider it important to follow inherited traditions" are less likely to approve cohabitation. Age also has an impact in both countries, indicating that older people are less likely to approve cohabitation. In 2018, some differences are noticed. In the case 
of the Spanish model, more predictors have to be included because education level and religion are not significant, while in the case of Poland, both variables keep its positive contribution to understand the dependent variable.

\section{References}

Billari, F.C. (2005). Choices, opportunities and constraints of partnership, childbearing and parenting: The patterns in the 1990s. In: Macura, M., MacDonald, A., \& Haug, W. (eds.), The new demographic regime: Population challenges and policy responses (pp. 63-94). Geneva, Switzerland: United Nations.

Bukodi, E. (2012). Serial cohabitation among men in Britain: Does work history matter? European Journal of Population/Revue européenne de Démographie, 28(4), pp. 441-466.

CSO, (2018). Demographic situation in Poland up to 2018. Families creation and dissolution. GUS, Warszawa.

CSO, (2020). Statistical Yearbook of the Republic of Poland. GUS, Warsaw.

Dommermuth, L. \& Wiik, Ka (2014). First, second or third time around? The number of co-residential relationships among young Norwegians. Young, 22(4), pp. 323-343.

Dominguez-Folgueras, M., Castro-Martin, T. (2013). Cohabitation in Spain: No longer a marginal path to family formation. Journal of Marriage and Family 75(2), pp. 422-437.

Ermisch, J. (2005). The Puzzling Rise in Childbearing Outside Marriage. In: Heath, A.F., Ermisch, J., Gallie, D. (ed.). Understanding Social Change. Oxford, Oxford University Press, 2005, pp. 23-53.

Eurostat, (28/06/2021). Share of live births outside marriage. https://ec.europa.eu/eurostat/ databrowser/view/tps00018/default/table?lang=en.

Eurostat, (29/06/2021). Archive: Marriages and Births in Spain. https://ec.europa.eu/eurostat/ statistics-explained/index.php?title=Archive:Marriages_and_births_in_Spain/es

Furstenberg, F.F. (2014). Fifty Years of Family Change: From Consensus to Complexity. Annals of The American Academy of Political and Social Science 654(1), pp. 12-30.

García-Pereiro, T. (2019). The role of trendsetters in the diffusion process of first cohabitations in Spain. Revista Espanola de Investigaciones Sociologicas, 166(June), 65-84. https:// doi.org/10.5477/cis/reis.166.65.

Giddens, A. (1993). The Transformation of Intimacy: Sexuality, Love and Eroticism in Modern Societies. Oxford: Polity Press.

Hoem, B. (1995). Sweden. In: Blossfeld, H.P. (ed.). The new role of women. Family Formation in Modern Societies. Boulder, Westview.

INE, (2020). Number of couples by type of union and sex of the couple (Continueus Household Survey, ECH). https://www.ine.es/jaxi/Datos.htm?path=/t20/p274/serie/ prov/p01/10/\&file $=01018$.px\#!tabs-tabla

Juszczyk-Frelkiewicz, K. (2014). Kohabitacja w Polsce i na Słowacji: studium socjolog- 
iczne w środowiskach studenckich/Cohabitation in Poland and Slovak Republic: sociological study in student circles. Katowice: Publishing House of the University of Silesia. Kiernan, K. (2002). Cohabitation in Western Europe: Trends, Issues and Implications. In: Booth, A., Crouter. A.C., (ed.). Just Living Together. Implications of Cohabitation on Families, Children, and Social Policy. The Pennsylvania State University.

Kiernan, K. (1999). Cohabitation in Western Europe. Population Trends 96, s. 25-32.

Kravdal, Ø. (1999). Does Marriage Require a Stronger Economic Underpinning than Informal Cohabitation?. Population Studies V. 53.

Lesthaeghe, R. (2010). The unfolding story of the Second Demographic Transition. Population and Development Review 36(2), pp. 211-251.

Lesthaeghe, R.J., Neidert, L. (2006). The Second Demographic Transition in the United States: Exception or textbook example? Population and Development Review 32(4), pp. 669-698.

McLanahan, S. (2004). Diverging destinies: how children are faring under the second demographic transition. Demography Nov; 41(4):607-27.

Manting, D. (1994). Dynamics in Marriage and Cohabitation. Amsterdam, Thesis Publishers.

Mills, M., Trovato, F. (2000). A comparative analysis of the Effect of Pregnancy in Cohabiting Unions on Formal Marriage in Canada, the Netherlands, and Latvia. United Nations Economic Commission for Europe’s Statistical Journal 17, pp. 1-16.

Mynarska, M., Matysiak, A. (2010). Diffusion of cohabitation in Poland. Studia Demograficzne 1(2): 157-158.

OECD, (2011). Families are changing. Retrieved from: https://www.oecd.org/els/ soc/47701118.pdf.

Nazio, T. (2008). Cohabitation, Family and Society. New York, Rutledge.

Perelli-Harris, B., Kreyenfeld, M. Sigle-Rushton, W., Keizer, R., Lappegård, T., Jasilioniene, A., Berghammer, C.,Di Giulio,P., (2012). Changes in union status during the transition to parenthood in eleven European countries, 1970s to early 2000s, Population Studies 66:2, pp. 167-182.

Rhoades, G.K., Stanley, S.M., Markman, H.J. (2009). Couples' reasons for cohabitation: Associations with individual well-being and relationship quality. Journal of Family Issues, 30(2), pp. 233-258.

Seltzer, J.A. (2004). Cohabitation in the United States and Britain: Demography, Kinship, and the Future. Journal of Marriage and Family 66 (4), pp. 921-928.

Surkyn, J., Lesthaeghe, R.J. (2004). Values orientations and the Second Demographic Transition (SDT) in Northern, Western and Southern Europe: An update. Demographic Research, S3(3), pp. 45-86.

Tomczak, Ł., Zawadzka, K. (2018). Polish political parties and their supporters with respect to same sex civil partnerships. Polityka i Społeczeństwo 1(16), pp. 132-145.

Toulemon, L. (1997). Cohabitation is Here to Stay. Population 9, pp. 11-46.

WVS, (2020). The Inglehart-Welzel World Cultural Map - World Values Survey 7 (2020)

[Provisional version]. Source: http://www.worldvaluessurvey.org/ 